\title{
Electoral Responsiveness and Partisan Bias in Multiparty Democracies
}

\section{Citation}

King, Gary. 1990. Electoral responsiveness and partisan bias in multiparty democracies. Legislative Studies Quarterly 15(2): 159-181.

\section{Published Version}

doi:10.2307/440124

\section{Permanent link}

http://nrs.harvard.edu/urn-3:HUL.InstRepos:4320362

\section{Terms of Use}

This article was downloaded from Harvard University's DASH repository, and is made available under the terms and conditions applicable to Other Posted Material, as set forth at http:// nrs.harvard.edu/urn-3:HUL.InstRepos:dash.current.terms-of-use\#LAA

\section{Share Your Story}

The Harvard community has made this article openly available.

Please share how this access benefits you. Submit a story.

\section{Accessibility}




\section{Electoral Responsiveness And Partisan Bias In Multiparty Democracies}

Because the goals of local and national representation are inherently incompatible, there is an uncertain relationship between aggregates of citizen votes and the national allocation of legislative seats in almost all democracies. In particular electoral systems, this uncertainty leads to diverse configurations of electoral responsiveness and partisan bias, two fundamental concepts in empirical democratic theory. This paper unifies virtually all existing multiyear seats-votes models as special cases of a new general model. It also permits the first formalization of, and reliable method for empirically estimating, electoral responsiveness and partisan bias in electoral systems with any number of political parties. I apply this model to data from nine democratic countries, revealing clear patterns in responsiveness and bias across different types of electoral rules.

In theory, electoral systems could be founded on the principle of either national or local representation. Those based on the principle of national representation would focus on political preferences without regard to geographic, religious, ethnic, and other lines of division. A system of local representation, in contrast, would preserve geographic and perhaps other subdivisions within a nation; such a system would be comprised of numerous semiautonomous, community-based political entities.

In practice, all democratic electoral systems embody features of both national and local representation. While founded on the premise that local communities should have a political voice, democratic systems must also devise mechanisms by which to integrate community-based political units into a functioning whole. Hence, most electoral systems are built on a two-tier aggregation process: in the first stage, preferences within geographic districts are aggregated; in the second, district-level preferences are combined.

The goals of national and local representation are not always compatible. In the process of synthesizing community preferences into a national will, minority interests are often subordinated to some de- 
gree. Additionally, even when the same standard of representation is applied at both the local and national levels, the two-tier process of aggregation can result in a system that fails to conform to the stated or desired standard. For example, consider a system in which proportional representation is guaranteed by law at the local level-in each and every multimember district-and constitutes the implicit national standard as well. In this type of system, political parties are not always represented in the legislature in exact proportion to their nation-wide vote totals, as a faithful embodiment of the proportional representation standard would have it. National proportional representation could be ensured by avoiding districts entirely, but such a system would sacrifice local representation.'

In other electoral systems, this aggregation effect has different consequences. For example, winner-take-all district-level electoral systems, such as those in the U.S. and Great Britain, generally do not translate into winner-take-all national systems of representation. Rather, the party with the nationwide majority typically acquires more, but not all, legislative seats. Thus the national minority parties are usually still represented.

Unfortunately the process of aggregating districts to the national level can also give rise to partisan bias. If a system is biased, some political parties are unfairly advantaged in that votes for the advantaged parties translate into a larger proportion of seats than they rightly deserve (Grofman 1983). In some nations, partisans control the process by which district lines are drawn and intentionally gerrymander the system to favor their party. However, even when redistricting is controlled by nonpartisan commissions or district lines remain unchanged, an electoral system can be biased; the spatial distribution or concentration of voters, the particular configuration of incumbents and challengers competing, differential turnout, changing voter preferences, or malapportionment can also give rise to asymmetries in the relationship between seats and votes. Whereas many different degrees of electoral responsiveness are reasonably considered desirable in different national systems-such as proportional representation or majoritarian systems-most theories of representation would have partisan bias reduced as much as possible. ${ }^{2}$

In this paper, I develop a general model of the uncertain relationship between aggregates of citizen votes and the allocation of legislative seats in democracies with any number of political parties and apply the model to data from nine democracies. This model permits the simultaneous estimation of the form of electoral responsiveness and the degrees and directions of partisan biases in multiparty systems. Special cases of this model include Taagepera (1986), Theil (1969), and 
Qualter's (1968) models of responsiveness in multiparty systems, Tufte (1973) and King and Browning's (1987) two-party models of responsiveness and bias, and numerous empirical applications and tests of the cube law of electoral politics (e.g., Kendall and Stuart 1950; Tufte 1973; Schrodt 1981).

With this general model, scholars can empirically estimate many features of electoral systems that previously were assumed or unknown. In addition, the results from nine democracies provide the first formal assessment of Taagepera's baseline electoral responsiveness predictions; several new empirical generalizations are derived for cases that deviate from these predictions. The analysis also demonstrates, both analytically and empirically, that previous attempts to estimate either electoral responsiveness or partisan bias in isolation-by far the dominant strategy - routinely leads to estimates that are very far off the mark. Furthermore, since previous multiparty models were inadequate or nonexistent, many scholars applied two-party models to multiparty systems; I demonstrate that this procedure also leads to very distorted estimates.

The next section reviews previous models. I then develop the new model and derive a maximum likelihood estimator. Applications are presented, and I discuss and summarize the empirical and theoretical implications of these results.

\section{Previous Results}

The first attempt to specify the relationship between nationwide legislative seats and citizen votes is the so-called cube law of electoral politics, formulated circa 1909 for two-party systems. Let $s$ be the proportion of seats and $v$ be the proportion of votes allocated to one of the political parties. Then, the cube law is a special form of the equation below, with $\rho=3$ (see Kendall and Stuart 1950):

$$
\frac{s}{1-s}=\left(\frac{v}{1-v}\right)^{\rho}
$$

Although scholars have long debated whether $\rho$ is 3.0 (as the cube law holds), 2.5 (Laakso 1979), or some other value, few would now argue that the relationship holds deterministically (as equation 1 implies) or even that $\rho$ is constant over time (Schrodt 1981).

As an electoral responsiveness parameter, $\rho$ has considerable political import: if $\rho=1$, legislative seats are allocated to the political parties in proportion to the division of citizen votes, exactly reflecting the division of citizen preferences. Figure 1 portrays this seats-votes 
FIGURE 1

Examples of Electoral Responsiveness

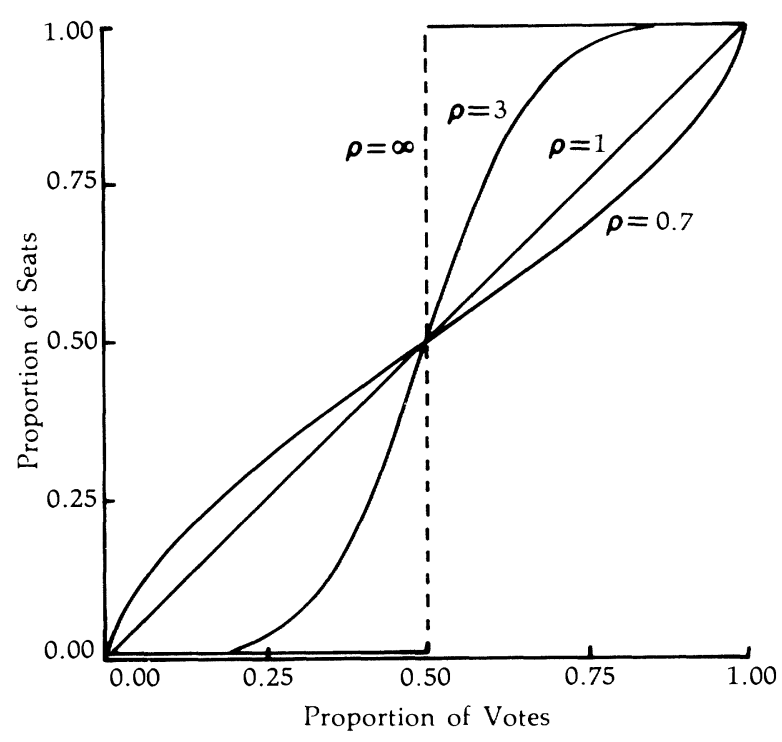

graph as a straight $45^{\circ}$ line. Larger values of $\rho$ give the majority party a "bonus" in seats over their share of the vote. For example, see the $\rho=3$ line in Figure 1. At the extreme value of $\rho=\infty$, the system is maximally responsive at the point where $v=0.5$, indicating a winner-take-all situation. Values of $\rho$ less than unity indicate eiectoral systems that are relatively unresponsive near the center of the graph, large changes in voter preferences translating only sluggishly into changes in the allocation of legislative seats. In general, the larger the value of $\rho$, the more responsive the electoral system is near the competitive region of state-wide votes. Note that this equation applies only to electoral systems assumed to be free of partisan bias, since, whatever the value of $\rho$, each party receives identical treatment.

For two-party electoral systems with single-member districts, Taagepera $(1973,1986)$ proposed that the electoral responsiveness parameter in equation 1 above be approximated by taking into account the total number of voters $\left(V=\sum_{j=1}^{J} v_{j}\right)$ and electoral districts $(D)$ in the nation:

$$
\rho \approx \frac{\ln (V)}{\ln (D)}
$$


Taagepera's justification for this specific mathematical relationship is based on the fact that it produces exactly correct results at the extremes and the assumption that the results for realistic cases (i.e., between the extremes) are quasi-continuous. For example, when each hypothetical electoral district is composed of a single voter $(D=V)$, proportional representation must result; indeed, equation 2 yields $\rho \approx \frac{\ln (V)}{\ln (D)}=\frac{\ln (D)}{\ln (D)}=1$. At the other extreme, when the nation is composed of a single, nationwide electoral district, and therefore all voters reside in the same district $(D=1)$, the system is winner-take-all and $\rho$ tends toward infinity (since $\ln (1)=0)$.

Between the extremes of $\rho=1$ and $\rho=\infty$, equation 2 need not hold at all for real elections because many factors others than $V$ and $D$ can influence the value of $\rho$, including gerrymandering, variations in partisan swing, the geographic distributions of partisan preferences, and variations in turnout. In addition, empirical values of $\rho$ can range below 1.0, indicating unresponsiveness, something Taagepera's index cannot do. However, the index does provide a method of generating quick, baseline predictions of $\rho$ that have sometimes proved quite accurate (Lijphardt 1985).

Now consider two completely separate generalizations of the basic relationship in equation 1 .

\section{Generalization to Multiparty Systems}

Theil (1969; see also Qualter 1968) studied the following multiparty generalization of the two-party cube law:

$$
s_{j}=\frac{v_{j}^{\rho}}{\sum_{m=1}^{J} v_{m}^{\rho}}
$$

where this relationship is assumed to hold for every party $j(j=1, \ldots, J)$. Theil did not postulate a particular value for the exponent $\rho$, but $\rho=1$ still indicates proportional representation, $\rho>1$ assigns the parties with more votes a bonus in legislative seats, and $\rho<1$ again indicates that the allocation of seats is relatively unresponsive to changes in legislative votes.

Taagepera (1986) also proposed a mathematical equation for predicting $\rho$-the electoral responsiveness parameter in equation 3 -analogous to that for two-party systems (in equation 2):

$$
p \approx\left[\frac{\ln (V)}{\ln (D M)}\right]^{1 / M}
$$


where $M$ is the district magnitude, the number of seats allocated to the reference party in each electoral district through proportional representation or some other method. In single-member district systems $(M=1)$, this equation reduces to equation 2 . In order to apply equation 4 to real electoral data, Taagepera introduced the relatively restrictive (and internally inconsistent) procedure of "assuming that every party . . f faces $N-1$ other parties of equal size in terms of votes" $(1986,494)$. This assumption leads to the following expression in lieu of equation 3 :

$$
s_{j}=\frac{v_{j}^{\rho}}{v_{j}^{\rho}+(N-1)^{1-\rho}\left(1-v_{j}\right)^{\rho}}
$$

where $N$ is the number of effective parties in an electoral system (see Lijphart 1984 and Laakso and Taagepera 1979):

$$
N=\frac{1}{\sum_{j=1}^{J} v_{j}^{2}}
$$

Taagepera (1986) applies his method to data from eight democracies and concludes that equation 4 predicts quite well.

\section{Generalization to Two-Party Systems with Partisan Bias}

The second generalization to equation 1 moves in a different direction. Instead of generalizing to multiple parties, Tufte (1973) and King and Browning (1987) also generalize from equation 1 by introducing partisan bias as a separate parameter, leaving intact the assumption of two parties. Niemi and Deegan (1978), King and Browning (1987), and others define a fair electoral system as one in which, if one party received $y \%$ of the seats for $x \%$ of the votes, then the other party would be allocated the same $y \%$ of the seats if it were to receive $x \%$ of the votes. Note that $x \%$ of votes need not translate (proportionately) into $x \%$ of seats for an electoral system to satisfy this fairness criterion. Indeed, defining fairness as partisan symmetry classifies many different forms of electoral systems as fair; these systems, in turn, can be ordered according to the degree of electoral responsiveness. Partisan bias is then defined as deviations from partisan symmetry, where one party can receive a larger share of the seats for a given share of votes than the other.

King and Browning (1987) implemented these ideas by modi- 
fying equation 1 in two ways. ${ }^{3}$ First, they included a partisan bias parameter, $\lambda$ :

$$
\frac{s}{1-s}=e^{\lambda}\left(\frac{v}{1-v}\right)^{\rho}
$$

As before, $\rho$ is the electoral responsiveness parameter. $\lambda$, a completely distinct parameter, indexes the degree and direction of partisan bias. $\lambda=0$ indicates the absence of partisan bias; in this case equation 7 reduces to equation 1. $\lambda>0$ indicates partisan bias in favor of the reference party (the party for which $v$ is its proportion of legislative votes), and $\lambda<0$ occurs when the electoral system is biased in favor of the opposing party.

Second, King and Browning explicitly incorporate a stochastic relationship by assuming that the probability of all districts allocating their seats to the reference party within an election year are independent and identically distributed. These two simplifying assumptions are the requisite first principles used to derive the binomial distribution for the number of seats allocated to the reference party. ${ }^{4}$ The systematic component is then derived by solving equation 7 for $s$, and writing the basic relationship as an expectation:

$$
\begin{aligned}
E(s) & =\left[1+e^{-\lambda}\left(\frac{1-v}{v}\right)^{\rho}\right]^{-1} \\
& =\left\{1+\exp \left[-\lambda-\rho \ln \left(\frac{v}{1-v}\right)\right]\right\}^{-1}
\end{aligned}
$$

The first line of this equation is a relatively simple algebraic expression, whereas the second shows how similar this expression is to the popular logit statistical model for analyzing binary dependent variables. King and Browning refer to this expression, a logit $\ln [v /(1-v)]$ embedded within an inverse logit, as the bilogit functional form. Note that $s$, denoting the proportion of seats, is now a random variable assumed to be related to the right hand side of this expression only in expectation (that is, on average across a large number of hypothetical elections held under essentially identical conditions). The relationship is utilized to derive a maximum likelihood estimator to calculate $\hat{\rho}$ and $\hat{\lambda}$ from real electoral data. 


\section{A Model of Electoral Responsiveness and Partisan Bias}

These two divergent generalizations from the original cube law-first to multiparty systems and, subsequently, to incorporate bias as well as electoral responsiveness in only two-party systems-are incorporated simultaneously in this paper. Although partisan bias is a more familiar concept in the U.S. and other countries with singlemember districts, the same phenomenon can exist in any nation with national standards for representation and district-based elections. ${ }^{5}$ The combination of these two contributions in a single model permits the first adequate assessment of Taagepera's predictions for $\rho{ }^{6}$ Since his predictions of $\rho$ depend on only three features of electoral systems $(M$, $V$, and $D$ ), they also provide very useful baseline figures to which actual election results, which depend on many other factors as well, can be compared. Thus, although the model developed in this section is primarily a statistical one, it builds on the advantages of both of the preceding approaches.

To derive a model of partisan bias and electoral responsiveness in multiparty electoral systems, I begin with equation 3 and add parameters for partisan bias. Recall that King and Browning added a single parameter to represent partisan bias for two political parties. ${ }^{7}$ I generalize this logic by adding $J-1$ partisan bias parameters for an electoral system with $J$ political parties. The extent to which an electoral system is biased for or against a party will be reflected in comparisons of these bias coefficients. This procedure is similar to including $K-1$ dummy variables in a linear regression to represent $K$ category nominal variable. The particular functional form is a straightforward generalization of both equation 3 and equation 7 :

$$
E\left(s_{j}\right)=e^{\lambda_{j}} \frac{v_{j}^{\rho}}{\sum_{m=1}^{J} e^{\lambda m} v_{m}^{\rho}}
$$

for $j=1, \ldots, J$ parties. $\rho$ is the electoral responsiveness parameter, with the same interpretation as in previous models. $\lambda_{1}, \ldots, \lambda_{J}$ are the partisan bias parameters, one for each of $J$ parties. To eliminate the repetitive information in the bias parameters, let $\lambda_{1}=0$; then $\lambda_{j}$ measures partisan bias from the $j^{\text {th }}$ party relative to the party 1 baseline. Thus, $\lambda_{2}$ is the bias toward party 1 compared to the bias toward party 2 : if $\lambda_{2}=0$ then parties 1 and 2 are symmetric and the system is fair at this point; if $\lambda_{2}>0$ then the electoral system unfairly favors party 2 over party 1 ; if 
$\lambda_{2}<0$, then the system favors 1 over 2 . The choice of which party to use as the reference party ("party 1 ") is completely arbitrary and has no substantive consequence. For example, although the estimates will provide comparisons of parties 1 and 2 and comparisons of 1 and 3, one can easily derive a comparison of parties 2 and 3 by taking the difference between the other two coefficients. Note that without making a series of unnecessary and unrealistic assumptions, multiparty versions of these models cannot be easily represented in graphical form since they would require four or more dimensional graphs. However, since the $\rho$ and $\lambda_{1}, \ldots, \lambda_{J}$ parameters have considerable meaning on their own, litthe is lost by using only the mathematical form.

This generalized relationship is formulated such that special cases include all previous models reviewed above. If $J=2$, equation 9 reduces to equation 8, from King and Browning (1987). If a system is unbiased and Taagepera's (1986) simplifying assumption that all opposition parties receive exactly the same proportion of the vote for all elections holds, this model reduces to equation 5. If $\lambda_{1}=\lambda_{2}=\ldots=\lambda_{J}=0$, the model reduces to equation 3 , from Theil (1969) and Taagepera (1986). If $\lambda_{1}=\lambda_{2}=\ldots=\lambda_{J}=0$ and $J=2$, equation 9 reduces to the original relationship in equation 1 , and if, in addition, $\rho=3$, it reduces to the cube law.

Without any of these restrictions, this form makes it possible to distinguish these special cases and a variety of others from empirical data instead of making unfounded assumptions. Indeed, since no restrictions like these are required, the method is ideally suited to analyzing actual election results. It even makes Taagepera's predictions of $\rho$ more useful as a baseline to which to compare real empirical estimates. Finally, by including parameters for electoral responsiveness and partisan bias in the same multiparty equation, this model enables one to avoid the statistical inconsistencies that would arise by trying to estimate only one of these parameters without the other.

\section{A Maximum Likelihood Estimator}

This section, which may be skipped without loss of continuity, describes how one can use observed electoral results to estimate $\rho$ and $\lambda_{2}, \ldots, \lambda_{J}$ in equation $9 .{ }^{8}$ Begin with some new definitions: let $S_{i j}$ be a random variable for the number of seats allocated to party $j$ at election $i$, the observed realization of which is $s_{i j}$. This variable is defined for $i=1, \ldots, n$ elections and $j=1, \ldots, J_{i}$ parties. $J_{i}$ is the number of parties competing in election $i$ and $J=\max \left(J_{i}\right)$ is the maximum number of parties competing in any election. Let $s_{i}=\sum_{j=1}^{J_{i}} s_{i j}$ be the number of seats 
available at election $i, v_{i j}$ be the proportion of votes for party $j$ at election $i$, and $\pi_{i j}$ be the average probability that one of the $s_{i}$ seats will be allocated to party $j$ in election $i ; E_{i}$ is the set of parties contesting election $i$. Finally, I summarize the data and probabilities in matrix form by election, $\boldsymbol{s}_{i}=\left\{s_{i 1}, \ldots, s_{i J}\right\}, \boldsymbol{\pi}_{i}=\left\{\pi_{i 1}, \ldots, \pi_{i J}\right\}$, and by election and party, $\boldsymbol{s}=\left\{s_{i j}\right.$; $\left.\mathrm{i}=1, \ldots, n ; j=1, \ldots, J_{i}\right\}$ and $\pi=\left\{\pi_{i j} ; i=1, \ldots, n ; j=1, \ldots, J_{i}\right\}$.

The assumptions required to derive the stochastic model are essentially the same as in the two-party case-independence and identical distributions across districts within an election year. However, these are primarily for mathematical convenience. If they happen to be false, parameter estimates will still be statistically consistent (see Gourieroux, Monfort, and Trognon 1984); roughly, this means that with an infinite sample of data, the estimator will yield the true parameter values (see King 1989a, ch. 4, for a precise statement). However, even with consistent parameter estimates, the estimated standard errors can be inconsistent if certain variance assumptions are not exactly correct. To avoid inconsistent standard errors, I report only robust standard errors, an alternative standard error estimator that is consistent in the presence of many types of misspecification (see Gallant and White 1988).

Furthermore, the implied assumption of independence of irrelevant alternatives is satisfied here, since the entire stochastic component is conditional on all parties and votes. The only random choice being made is by the electoral system in assigning seats to parties. Therefore I use the multinomial probability distribution for the numbers of seats allocated to the $J$ political parties, a straightforward generalization of the binomial:

$$
\begin{aligned}
\left(\mathbf{S}_{i 1}, \ldots, S_{i J_{i}}\right) & \sim \operatorname{Multinomial}\left(\mathbf{s}_{\mathbf{i}} \mid \boldsymbol{\pi}_{i}\right) \\
& =s_{i} ! \prod_{j \in E_{i}} \frac{\pi_{i j}^{s_{i j}}}{s_{i j} !}
\end{aligned}
$$

The systematic component comes directly from equation 9:

$$
\begin{aligned}
\frac{E\left(S_{i j}\right)}{s_{i}} \equiv \pi_{i j} & =\frac{e^{\lambda j} v_{i j}^{\rho}}{\sum_{k \in E_{i}} e^{\lambda_{k} v_{i k}^{\rho}}} \\
& =\frac{\exp \left(\lambda_{j}+\rho \ln v_{i j}\right)}{\sum_{k \in E_{i}} \exp \left(\lambda_{k}+\rho \ln v_{i k}\right)}
\end{aligned}
$$


for parties $j=1, \ldots, J_{i}$, elections $i=1, \ldots, n$, and $\lambda_{1}=0$. The first line in this equation is a relatively simple expression, whereas the latter demonstrates the similarity of this "multinominal bilogit" model to the popular multinominal logit statistical model used for analyzing multicategory, nominal-level dependent variables. The stochastic component in equation 10, which is not designed for nominal-level dependent variables, prevents one from merely adopting the multinomial logit model in full (with a substitution of variables).

To estimate the unknown parameters $\rho$ and $\lambda_{2}, \ldots, \lambda_{J}$, I use the method of maximum likelihood. The basic idea is to derive the likelihood function by substituting the right hand side of equation 11 for $\pi_{i j}$ in equation 10. Given the observed data and the model, the goal is then to choose values of the unknown parameters that have the maximum likelihood of having produced the data we actually observe (see King 1989a).

First form the likelihood function by assuming the independence of electoral results over time and thus taking the product of equation 10 over the $n$ observed elections in the sample. The log-likelihood is generally easier to work with, and the values of the parameters that maximize it are the same as those that maximize the original likelihood. The log-likelihood is then written as follows:

$$
\ln L(\pi \mid \mathbf{s})=\sum_{i=1}^{n}\left\{\ln \left(s_{i} !\right)+\sum_{j \in E_{i}}\left[s_{i j} \ln \left(\pi_{i j}\right)-\ln \left(s_{i j} !\right)\right]\right\}
$$

Since likelihood is a relative concept only, we can simplify this equation by dropping terms that do not depend on the parameters:

$$
\ln L(\pi \mid \mathbf{s})=\sum_{i=1}^{n}\left\{\sum_{j \in E_{i}} s_{i j} \ln \left(\pi_{i j}\right)\right\}
$$

Finally, we substitute the right hand side of equation 11 into this expression to yield the final form of the log-likelihood:

$$
\begin{aligned}
& \ln L\left(\rho, \lambda_{2}, \ldots, \lambda_{J} \mid \mathbf{s}\right)= \\
& \sum_{i=1}^{n}\left\{\sum_{j \in E_{i}} s_{i j}\left[\lambda_{j}+\rho \ln \left(v_{i j}\right)-\ln \left(\sum_{k \in E_{i}} e^{\lambda_{k}+\rho \ln v_{i k}}\right)\right]\right\}
\end{aligned}
$$

Parameter estimates result when this function is maximized with respect 
to the unknown parameters, and robust standard errors are derived from the curvature of the likelihood function at this maximum. The presence of the last term in parentheses, a function of both $\lambda$ and $\rho$, is the direct evidence that the two parameters cannot be estimated separately. Attempting to do so can only result in inconsistent statistical estimates: even if an infinite amount of electoral data were available, one would still get the wrong answer. Unfortunately, this result calls into question all previous empirical seats-votes analyses of multiparty systems. ${ }^{9}$

\section{Empirical Analyses}

In this section, I apply the new model developed above to data from nine democratic electoral systems. I maximize comparability across research efforts and diversity across electoral systems by using the eight democracies that Taagepera (1986) analyzed. To this list, I add Great Britain because of the long history of seats-votes research in and about that nation. Data were collected and cross-checked from a variety of sources. ${ }^{10}$

Estimates of $\rho$ and $\lambda_{2}, \ldots, \lambda_{J}$, along with robust standard errors, appear in Tables 1-3. I also report the average value of Taagepera's prediction for $\rho$, based on equation 4 . The latter differs marginally from those reported in Taagepera (1986) because I have updated all his data with more recent elections. After a somewhat more detailed look at the results from Great Britain, I describe these estimates of the national system of representation in all nine countries in separate subsections, according to their formal district-level electoral laws: single-member districts, plurality voting; multimember districts with modified proportional representation, and multimember districts with proportional representation. For all systems, the choice of which political parties to include in the model was based on knowledge of and previous research on the individual countries, the index of effective parties in equation 6 , and additional specification testing.

Table 1 presents three sets of results for Great Britain. The first set is estimated under the assumption that partisan bias is zero; the second allows for partisan bias but forces the three British parties into a two-party model (by using only the Labour and Conservative proportions of the two-party vote and seat allocation); the final set is the full unrestricted version. To the extent that these results differ and one is unsure of the true model, as is usually the case, the fully unrestricted version is preferred. 
TABLE 1

Electoral Responsiveness and Partisan Bias in National Systems with Single-Member Districts

(standard error in parentheses)

\begin{tabular}{|c|c|c|c|}
\hline Nation & $\begin{array}{l}\text { Model Assuming } \\
\text { No Partisan Bias }\end{array}$ & $\begin{array}{l}\text { Two-Party } \\
\text { Model }\end{array}$ & $\begin{array}{c}\text { Unrestricted } \\
\text { Model }\end{array}$ \\
\hline \multicolumn{4}{|l|}{ Great Britain, $1950-87^{a}$} \\
\hline Responsiveness & $\begin{array}{l}2.59 \\
(0.20)\end{array}$ & $\begin{array}{l}1.60 \\
(0.24)\end{array}$ & $\begin{array}{l}1.14 \\
(0.24)\end{array}$ \\
\hline Bias toward Labour & & $\begin{array}{l}-0.01 \\
(0.02)\end{array}$ & $\begin{array}{c}-0.05 \\
(0.02)\end{array}$ \\
\hline $\begin{array}{l}\text { Bias toward Liberal } \\
\text { and Alliance Parties }\end{array}$ & & & $\begin{array}{l}-1.60 \\
(0.16)\end{array}$ \\
\hline \multicolumn{4}{|l|}{ United States, $1946-86^{h}$} \\
\hline Responsiveness & $\begin{array}{l}2.21 \\
(0.17)\end{array}$ & & $\begin{array}{l}1.78 \\
(0.24)\end{array}$ \\
\hline Bias toward Republicans & & & $\begin{array}{l}-0.11 \\
(0.04)\end{array}$ \\
\hline \multicolumn{4}{|l|}{ Canada, $1921-84^{c}$} \\
\hline Responsiveness & $\begin{array}{c}1.24 \\
(0.06)\end{array}$ & & $\begin{array}{l}1.82 \\
(0.13)\end{array}$ \\
\hline Bias toward Liberal Party & & & $\begin{array}{l}-0.01 \\
(0.01)\end{array}$ \\
\hline $\begin{array}{l}\text { Bias toward NDP and Other } \\
\text { Parties }\end{array}$ & & & $\begin{array}{l}-0.10 \\
(0.03)\end{array}$ \\
\hline
\end{tabular}

${ }^{a}$ The reference party is the Conservatives; Taagepera's Index $=2.71$.

${ }^{b}$ The reference party is the Democrats; Taagepera's Index $=2.94$.

'The reference party is the Conservatives; Taagepera's Index $=2.81$.

Note first that estimates of responsiveness $(\rho)$ change considerably across the three specifications. In addition, the estimate for partisan bias between the Conservative and Labour parties increases from an apparently negligible level, in the two-party model, to a moderate level significantly different from zero, in the unrestricted model.

These results underscore the benefits of this more general model and the considerable distortions that can arise in using the more restrictive models previously developed in the literature. Much of what appeared to be responsiveness in a large number of studies of the British system was merely a bias favoring the larger parties: if the Liberals were to receive a majority of votes in some future election, they would not re- 
ceive as large a bonus in seats as either the Labour party or the Conservative party have received when they are in the majority. ${ }^{11}$

\section{Single-Member District Systems}

Britain, the U.S., and Canada are the only three democracies in the sample composed of single-member districts (see Table 1). Estimates of responsiveness $(\rho)$ differ considerably across the specifications for each country. Including the bias parameters reduces the estimate of electoral responsiveness, $\rho$, in the U.S. and Britain; in contrast, incorporating the bias parameters in Canada makes the estimate of $\rho$ larger. Thus, the statistical problems caused by assuming the absence of partisan bias in previous research can have varying consequences in different democracies. ${ }^{12}$ Major political parties in the U.S., Britain, and Canada all experience some amount of partisan bias statistically distinguishable from zero. In Britain, the Conservatives are favored slightly over the Labour party, and both are enormously advantaged over the Liberals. The U.S. system is moderately biased in favor of the Democratic and against the Republican party. In Canada, the two major parties are on roughly equal footing, but the smaller parties are clearly disadvantaged. In Table 1 , all minor parties in Canada are grouped together. A more detailed analysis of these individual parties (not shown) indicates that the system is biased somewhat more against the NDP, since their limited voter support is diffused throughout the country (except Quebec), but less against many of the small regional parties, where fewer votes are wasted.

In all three nations, Taagepera's baseline prediction for $\rho$ is larger than the empirically based estimate. Since the three predictions are all considerably further than two standard deviations away, we can be quite confident that these are discrepancies due to systematic prediction errors rather than the merely random fluctuations inherent in every electoral system.

\section{Modified Proportional Representation Systems}

Austria and Japan both use multimember districts, but the number of legislators elected in each district is smaller than in every other proportional representation system in the sample. The situation is also complicated in Austria since, in 1971, the electoral system was changed to one with much larger district magnitudes (see Lijphardt et al. 1988, Appendix). In addition, voters in Japan cast only a single 
TABLE 2

Electoral Responsiveness and Partisan Bias in National Systems with Modified Proportional Representation

(standard error in parentheses)

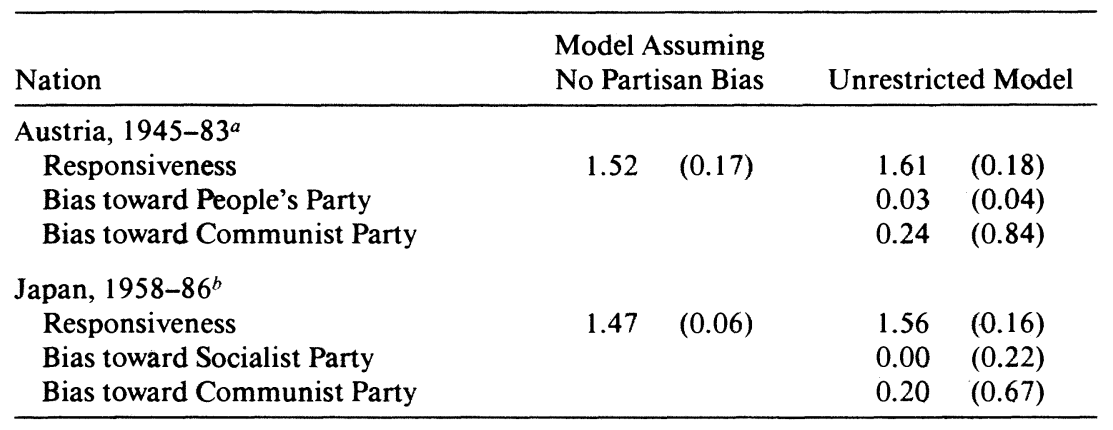

${ }^{a}$ The reference party is the Socialists; Taagepera's Index $=1.15$.

${ }^{b}$ The reference party is the Liberal Democrats; Taagepera's Index $=1.38$.

ballot for one candidate of their choice. Estimates, standard errors, and Taagepera's index are shown in Table 2 for Austria and Japan.

In these systems, partisan bias is never as much as a single standard error from zero. Taagepera's predictions for $\rho$ are closer to the empirical estimates for these countries than for the single-member district nations. Nevertheless, both predictions are underestimates: Although the coefficient for Japan is only a little more than a single standard deviation above Taagepera's predictions, the Austrian coefficient is nearly half a point (more than two standard errors) too high. These results suggest that some feature of these electoral systems may not have been captured by Taagepera's Index. ${ }^{13}$

\section{Proportional Representation Systems}

The final category of nations is composed of the traditional proportional representation systems. These include Italy, the Netherlands, Finland, and Switzerland. This category is fairly broad, and the electoral systems represented in it are quite diverse. The Netherlands, for example, has only a single national district with all 150 legislative seats, effectively sacrificing local representation entirely. At the other extreme, Italy elects 630 members to its Chamber of Deputies from 32 geographic electoral districts. Moreover, the degree of importance attached to districtlevel representation is but one of many dimensions along which these electoral systems differ (see Lijphart 1984, 1986; Rae 1971). 


\section{TABLE 3}

Electoral Responsiveness and Partisan Bias in National Systems with Proportional Representation

(standard error in parentheses)

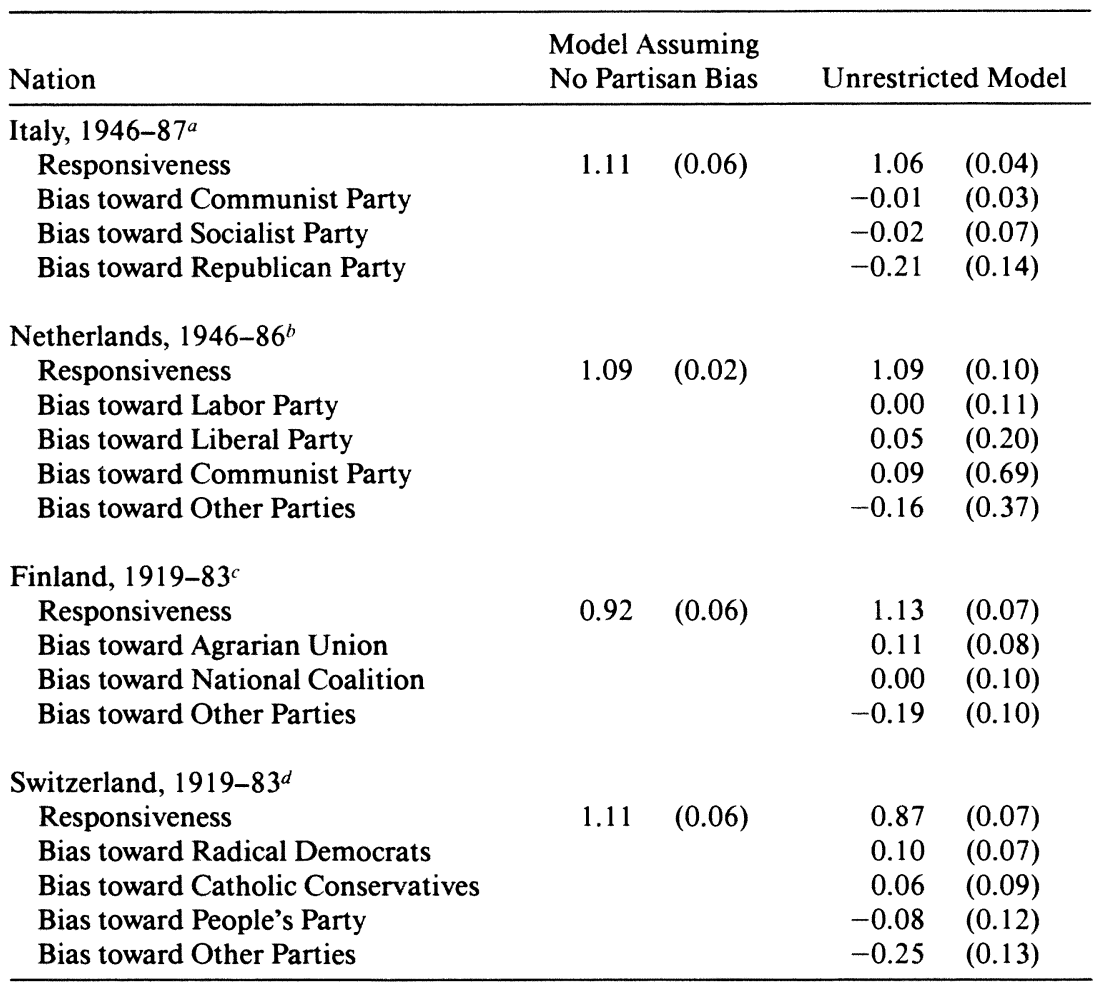

${ }^{a}$ The reference party is the Christian Democrats; Taagepera's Index $=1.06$.

${ }^{b}$ The reference party is the Christian Democratic Appeal; Taagepera's Index $=1.01$.

'The reference party is the Social Democrats; Taagepera's Index $=1.08$.

$d$ The reference party is the Social Democrats; Taagepera's Index $=1.14$.

As diverse as these four countries are, however, the empirical results indicate quite similar rules for the translation of citizen votes into the allocation of legislative seats. With the possible exception of Switzerland, which appears slightly unresponsive (since $\rho<1$ ), all four have $\rho$ quite close to 1.0 , indicating proportional representation on the national level. The proportional representation legislated in each multimember district need not have been preserved at the national level in any nation but the Netherlands, which has a single nation-wide 
district, but in practice it was preserved for all four nations. ${ }^{14}$ In some cases, ad hoc modifications of district-level proportional representation may also have pushed the electoral system toward this result, as in Italy where surplus votes are pooled at the national level for reallocating unfilled seats.

Although there is a common tendency for the smaller parties to be at some disadvantage relative to the larger ones, all partisan bias parameters are within two standard errors of zero. A final distinctive feature of these four democracies is that Taagepera's baseline predictions for $\rho$ are almost perfect in every case. The one partial exception is Switzerland, where the empirical estimates were lower than the prediction. This problem may occur because Taagepera's Index is constructed so that it can never drop below 1.0, whereas in actual electoral systems $\rho$ can range between zero and positive infinity. Except for this country, we must conclude that deviations from Taagepera's predictions in this category are not clearly distinguishable from random variability.

\section{Discussion}

In this section, I speculate about the reasons for some of the empirical findings described above. First, why are Taagepera's baseline electoral responsiveness predictions clearly too large in single-member district systems, slightly too small in modified proportional representation systems, and right on target in traditional proportional representation systems? The key is that these predictions are based solely on exogenous features of electoral systems-the total numbers of voters $(V)$, districts $(D)$, and seats per district $(M)$-and should not be expected to pick up other phenomena in electoral politics. For example, voters in single-member district systems are somewhat more likely to develop loyalties to individual candidates than are voters in multimember districts (Cain, Ferejohn, and Fiorina 1987). This tendency, along with higher probabilities of partisan (Owen and Grofman 1988) and bipartisan (Mayhew 1971) gerrymandering, increases the probability of incumbency voting (see also Erikson 1972; Fiorina 1977; Ferejohn 1977; and Cain 1985). Incumbency voting, in turn, has formally been shown to reduce the responsiveness of electoral systems, even after partisan bias is accounted for (King 1989b). In other nations, the same phenomenon could also occur-again reducing electoral responsiveness below the baseline predictions-but multimember districts make this much less likely.

In Japan and Austria, Taagepera's baseline predictions are much closer to the mark, but seem to be consistently low, perhaps be- 
cause of random error or other features of these electoral systems not incorporated in the index. For example, the index does not incorporate particular voting methods or ways of aggregating votes, once cast. As was mentioned above, these methods do differ in ways that bring these systems somewhat closer to single-member district systems. This fact alone might account for empirical estimates that are more responsive than the baseline predictions. Other possible explanations relate to unique circumstances in these two countries. Members of the Japanese Diet, for example, may tend to switch parties at unusually high rates (Ward 1978). Since voters tend to remain loyal to their candidates after party switches (as long as the candidates choose parties with similar ideological platforms), the balance of power among the parties is much more fluid in Japan than in other nations. This condition might make the allocation of legislative seats among the political parties more responsive to changes in voter preferences.

The Austrian system is frequently an anomaly in empirical theories of comparative politics (Carstairs 1980,134). In this case, the result may be due to dynamics of the party system: although the electoral system features multimember districts and a form of proportional representation, Austria has a surprisingly small number of political parties (2.5 effective parties on average). The explanation for this small number of parties may be that "divisive political forces were too few and too weak" (Rae 1971, 95) or it may be the unusually strong dependence of voting behavior on the social structure (Haerpfer and Gehmacher 1984; Sully 1981). These factors may also make the electoral system somewhat more majoritarian than Taagepera's Index would predict on the basis of other electoral characteristics.

Two other empirical generalizations are worthy of comment. First, the likelihood of partisan bias appears to be dramatically reduced in systems with multimember districts. Consequently, one solution to the problem of gerrymandering could be to move to multimember districting systems. In the U.S., for example, multimember districts are widely used in state and local elections, but these generally operate under at-large, rather than proportional representation, rules. As a result, they are often used to dilute the strength of racial and other minorities-increasing rather than decreasing partisan (and other forms of) bias. ${ }^{15}$ Thus, multimember districts would probably need to be combined with proportional representation within districts in order to reduce biases. However, as this type of system was found here to produce a relatively low level of electoral responsiveness, at about $\rho=1$, it is unlikely to be politically popular. Although scholars and political reformers in many countries insist on a standard of proportional representa- 
tion, with $\rho=1$, scholars in the U.S. worry about the fate of democracy as they observe $\rho$ declining in recent years from about 3.0 to nearly 2.0.16 This is a fundamental disagreement in normative criteria for judging representative democracy that has not been resolved or, before now, even mentioned.

Finally, in most of the nations analyzed above, electoral systems tend to favor the largest parties. Even in the proportional representation systems, with $\rho$ near 1.0 , point estimates for partisan bias were slightly negative for the smallest parties, although not significantly so. Threshold levels of exclusion and representation in each district (Lijphart and Gibberd 1977), majority party gerrymandering, or bad spatial distributions of minority party voters (Gudgin and Taylor 1979) could also help account for this pattern. Alternatively, it may be due to a simultaneity problem: the largest parties often were instrumental in setting up the existing form of the electoral system, presumably with their own electoral strengths and weaknesses in mind. But even if their influences does not extend back to the inception of the system, majority parties in most nations have the power to change the system now and choose not to do so, again presumably because it benefits their party. If this presumption were correct, we would observe electoral systems that apparently benefit any large party but that in fact give the biggest boost to the current large party-something only the method presented here is capable of distinguishing. The British case may speak to this pattern.

\section{Conclusions}

Because the goals of local and national representation are inherently incompatible, there is an uncertain relationship between aggregates of citizen votes and the national allocation of legislative seats. In the context of particular electoral systems, this uncertainty leads to diverse configurations of electoral responsiveness and partisan bias, two fundamental concepts in empirical democratic theory.

This paper contributes to the literature by unifying existing seats-votes models as special cases of a new general model. It also permits the first formalization of, and reliable method of empirically estimating, electoral responsiveness and partisan bias in electoral systems with any number of political parties.

The empirical applications of this model to legislative elections in nine democratic electoral systems also led to a variety of interesting empirical results, showing that Taagepera's Index of electoral responsiveness predicts well in certain cases. In others, however, responsiveness depends on many factors beyond the three included in his 
deterministic index. The results also demonstrate the dangers of the restrictive assumptions inherent in much previous research.

\author{
Gary King is Professor of Government, Harvard University, \\ Cambridge, Massachusetts 02138.
}

\title{
NOTES
}

Thanks to Dick Katz, Arend Lijphart, Bob Putnam, Ken Shepsle, Rein Taagepera, and Andrew Gelman for many helpful comments; Jo Andrews, Nancy Burns and Bob Scarborough for research assistance; and the National Science Foundation for research grants SES-87-22715 and SES-89-09201.

1. One of the earliest, strongest, and most celebrated proponents of Hare's (1865) original proposal to implement proportional representation in a single nationwide district was John Stuart Mill (1867). Mill (1867, 1347-48) was also among the first to suggest a modification in order to foster local representation. Indeed, in the third edition of his book, Hare includes a new preface that responds to his critics' complaints about proportional representation's effect on localities (see also Hare 1865, chs. 2-4). In most nations where proportional representation has been adopted, Mill's specific proposal was not used, but most electoral laws do aim at improving local representation by applying a different form of proportional representation only within geographically distinct multimember districts.

2. In a minority opinion in the U.S. Supreme Court case of Davis v. Bandemer (1986), Justice O'Connor argued to the contrary that gerrymandering is one of the spoils to which the majority party should be entitled. The U.S. more generally accepts affirmative racial gerrymandering, and many nations intentionally weight the electoral results to overrepresent very sparsely populated areas of their countries.

3. Note that $\ln (\beta)$ in King and Browning (1987) is the same as $\lambda$ here.

4. If the binomial model is used but is incorrect, the statistical estimates will be somewhat inefficient but will still be consistent (Gourieroux, Monfort, and Trognon 1984).

5. Although their models differ primarily on substantive grounds, Taagepera and King and Browning also have different methodologies and scientific goals. Taagepera is primarily interested in formulating simple mathematical relationships that are useful for making baseline predictions, such as equations 2 and 4. Although expressed as deterministic relationships, they are meant more as approximations than as statements of some law of electoral politics. On the other hand, from the observed electoral data King and Browning wish to estimate values of $\rho$ and $\lambda$. Their approach is not designed for predicting parameters, but it does enable one to assess the state of arbitrary electoral systems with generalizations of well-accepted statistical methods.

6. Taagepera's $(1986,499)$ approach to empirical verification is "eyeballing" seats-votes graphs. Although useful for some purposes, this approach lacks precision and rigor. More important, distinguishing prediction errors that are due to random error from those due to systematic mistakes is quite hazardous. It turns out that significant information, missed with the graphical approach, can be extracted from the data with the methods proposed here.

7. This functional form is a special case of the multinomial logit model (see Amemiya 1985). However, this model cannot be estimated from within the multinomial logit framework.

8. A computer program to implement this estimator is available from the author. 
9. As an alternative stochastic component, I also tried a model in which the seat proportions were assumed to be multivariate normal on the logit scale. In virtually all cases, I found these parameter estimates to be similar to those presented below.

10. The data were collected and checked by comparing Mackie and Rose (1982) with Butler (1981), Japan Statistical Yearbook (1986, 1987), Leonard and Natkiel (1986), “National Elections" (1987), Nohlen (1978), Ornstein et al. (1984), Passin (1979), Rapport Statutaire du Directeur Général des Elections du Canada (1984), Smith (1985), and Van Loon and Whittington (1981).

11. This result obviously depends on where the Liberal party would receive their majority of votes. If they were to dramatically change their geographic base of support-an unlikely situation - they might very well receive as large a bonus as the Labour or Conservative parties.

12. This result is conceptually analogous to the statistical effect of omitted variable bias in linear regression analysis.

13. In a further analysis (not shown), I find that $\rho$ changes only marginally in Austria after 1971.

14. Omitting the "alliance" elections from the Italian data does not affect these substantive conclusions.

15. In addition, Niemi and Winsky (1987) show that at-large multimember districts in U.S. state legislatures have relatively high electoral responsiveness, as measured by rates of member turnover.

16. For example, Mayhew $(1974,314)$ refers to these trends in congressional elections as "the blunting of a blunt instrument." Fiorina $(1977,14)$ says "we face the possibility of a Congress composed of professional office holders oblivious to the changing political sentiments of the country." Brady (1988) argues that major congressional policy change is very unlikely with the current low level of electoral responsiveness.

\section{REFERENCES}

Amemiya, Takeshi. 1985. Advanced Econometrics. Cambridge, MA: Harvard University Press.

Brady, David W. 1988. Critical Elections and Congressional Policy Making. Stanford, CA: Stanford University Press.

Butler, David. 1981. "Electoral Systems." In Democracy at the Polls, ed. David Butler, Howard R. Penniman, and Austin Ranney. Washington, DC: American Enterprise Institute.

Cain, Bruce. 1985. “Assessing the Partisan Effects of Redistricting." American Political Science Review 79:320-33.

Cain, Bruce, John Ferejohn, and Morris Fiorina. 1987. The Personal Vote: Constituency Service and Electoral Independence. Cambridge, MA: Harvard University Press.

Carstairs, Andrew McLaren. 1980. A Short History of Electoral Systems in Western Europe. London: Allen and Unwin.

Davis v. Bandemer. 1986. 106 S.Ct. 2797.

Erikson, Robert S. 1972. "Malapportionment, Gerrymandering, and Party Fortunes in Congressional Elections." American Political Science Review 66:1234-45.

Ferejohn, John A. 1977. "On the Decline of Competition in Congressional Elections." American Political Science Review 71:166-76.

Fiorina, Morris. 1977. Congress: Keystone of the Washington Establishment. New Haven, CT: Yale University Press. 
Gallant, A. Ronald, and Halbert White. 1988. A Unified Theory of Estimation and Inference for Nonlinear Dynamic Models. Oxford: Basil Blackwell.

Gourieroux, C., A. Monfort, and A. Trognon. 1984. "Pseudo Maximum Likelihood Methods: Theory." Econometrica 52:681-700.

Grofman, Bernard. 1983. "Measures of Bias and Proportionality in Seats-Votes Relationships." Political Methodology 9:295-327.

Gudgin, G. and P.J. Taylor. 1979. Seats, Votes, and the Spatial Organization of Elections. London: Pion.

Haerpfer, Christian, and Ernst Gehmacher. 1984. "Social Structure and Voting in the Austrian Party System." Electoral Studies 3:25-46.

Hare, Thomas. 1865. The Election of Representatives: Parliamentary and Municipal. 3d ed. London: Longman, Green, Longman, Roberts, and Green.

Japan Statistical Yearbook. 1986. Statistics Bureau. Management and Coordination Agency.

Japan Statistical Yearbook. 1987. Statistics Bureau. Management and Coordination Agency.

Kendall, M.G., and A. Stuart. 1950. "The Law of Cubic Proportion in Election Results." British Journal of Sociology 1:183-97.

King, Gary. 1989a. Unifying Political Methodology: The Likelihood Theory of Statistical Inference. New York: Cambridge University Press.

King, Gary. 1989b. "Representation Through Legislative Redistricting: A Stochastic Model." American Journal of Political Science 33:787-824.

King, Gary, and Robert X Browning. 1987. "Democratic Representation and Partisan Bias in Congressional Elections." American Political Science Review 81: 1251-76.

Laakso, Markku. 1979. "Should a Two-and-a-Half Law Replace the Cube Law in British Elections?" British Journal of Political Science 9:355-84.

Laakso, Markku, and Rein Taagepera. 1979. "Effective Number of Parties: A Measure with Application to West Europe." Comparative Political Studies 12:3-27.

Leonard, Dick, and Richard Natkiel. 1986. World Atlas of Elections: Voting Patterns in 39 Democracies. London: The Economist Publications.

Lijphart, Arend. 1986. "Degrees of Proportionality of Proportional Representation Formulas." In Electoral Laws and Their Political Consequences, ed. Bernard Grofman and Arend Lijphart. New York: Agathon Press.

Lijphart, Arend. 1985. "Size, Pluralism, and the Westminster Model of Democracy: Implications for the Eastern Caribbean." Presented at the conference on Democracy, Development and Collective Security in the Eastern Caribbean: The Lessons of Grenada, San German, Puerto Rico.

Lijphart, Arend. 1984. Democracies. New Haven, CT: Yale University Press.

Lijphart, Arend, and Robert W. Gibberd. 1977. "Thresholds and Payoffs in List Systems of Proportional Representation." European Journal of Political Research 5:219-44.

Lijphart, Arend and collaborators. 1988. "The Political Consequences of Electoral Laws, 1945-1985: A Critique, Re-Analysis, and Update of Rae's Classic Study.” Presented at the XIVth World Congress of the International Political Science Association, Washington, DC.

Mackie, Thomas T., and Richard Rose. 1982. The International Almanac of Electoral History. 2d ed. London: MacMillan Press Ltd.

Mayhew, David R. 1971. "Congressional Representation: Theory and Practice in Drawing the Districts." In Reapportionment in the 1970s, ed. Nelson W. Polsby. Berkeley: University of California Press.

Mayhew, David R. 1974. "Congressional Elections: The Case of the Vanishing Marginals." Polity 6:295-317. 
Mill, John Stuart. 1867. "Personal Representation: Speech of John Stuart Mill, Esq., M.P." Delivered in the House of Commons, May 29, Hansard's Parliamentary Debates, Vol. 187, pp. 1343-56.

"National Elections." 1987. Electoral Studies 6:302.

Niemi, Richard, and John Deegan, Jr. 1978. "A Theory of Political Districting." American Political Science Review 72:1304-23.

Niemi, Richard G., and Laura R. Winsky. 1987. "Membership Turnover in U.S. State Legislatures: Trends and Effects of Districting." Legislative Studies Quarterly 12:115-23.

Nohlen, Dieter. 1978. Wahlsysteme der Welt [Electoral Systems of the World]. München: Piper.

Ornstein, Norman J., Thomas E. Mann, Michael J. Malbin, Allen Schick, and John F. Bibby. 1984. Vital Statistics on Congress, 1984-1985 Edition. Washington, DC: American Enterprise Institute.

Owen, Guillermo, and Bernard Grofman. 1988. "Optimal Partisan Gerrymandering." Political Geography Quarterly 7:5-22.

Passin, Herbert. 1979. "Japanese Politics Today." In A Season of Voting, ed. Herbert Passin. Washington, DC: American Enterprise Institute.

Qualter, Terence H. 1968. "Seats and Votes: An Application of the Cube Law to the Canadian Electoral System." Canadian Journal of Political Science 1:336-44.

Rae, Douglas W. 1971. The Political Consequences of Electoral Laws. Rev. ed. New Haven, CT: Yale University Press.

Rapport Statutaire du Directeur Général des Elections du Canada. 1984. Publié par le Directeur Général des Elections du Canada. Ministre des Approvisionnements et Services Canada.

Schrodt, Philip A. 1981. "A Statistical Study of the Cube Law in Five Electoral Systems." Political Methodology 7:31-53.

Smith, David E. 1985. "Party Government, Representation and National Integration in Canada." In Party Government and Regional Representation in Canada, ed. Peter Aucoin. Toronto: University of Toronto Press.

Sully, Melanie A. 1981. Political Parties and Elections in Austria. London: Hurst.

Taagepera, Rein. 1986. "Reformulating the Cube Law for Proportional Representation Elections." American Political Science Review 80:489-504.

Taagepera, Rein. 1973. "Seats and Votes: A Generalization of the Cube Law of Elections." Social Science Research 2:257-75.

Theil, Henri. 1969. “The Desired Political Entropy." American Political Science Review 63:521-25.

Tufte, Edward. 1973. “The Relationship Between Seats and Votes in Two-Party Systems." American Political Science Review 67:540-54.

Van Loon, Richard J., and Michael S. Whittington. 1981. The Canadian Political System. 3d ed. Toronto: McGraw-Hill Ryerson.

Ward, Robert E. 1978. Japan's Political System. 2d ed. Englewood Cliffs, NJ: Prentice-Hall. 